Review Article

\title{
Advantages of Phosphodiesterase Type 5 Inhibitors in the Management of Glucose Metabolism Disorders: A Clinical and Translational Issue
}

\author{
Cristina Antinozzi D, Paolo Sgrò, and Luigi Di Luigi \\ Unit of Endocrinology, Department of Movement, Human and Health Sciences, University of Rome "Foro Italico", \\ 00135 Rome, Italy \\ Correspondence should be addressed to Cristina Antinozzi; cristina.antinozzi@uniroma4.it
}

Received 25 May 2020; Revised 6 July 2020; Accepted 14 July 2020; Published 28 July 2020

Academic Editor: Pierlorenzo Pallante

Copyright $\odot 2020$ Cristina Antinozzi et al. This is an open access article distributed under the Creative Commons Attribution License, which permits unrestricted use, distribution, and reproduction in any medium, provided the original work is properly cited.

\begin{abstract}
Among metabolic diseases, carbohydrate metabolism disorders are the most widespread. The most common glucose pathological conditions are acquired and may increase the risk of type 2 diabetes, obesity, heart diseases, stroke, and kidney insufficiency. Phosphodiesterase type 5 inhibitors (PDE5i) have long been used as an effective therapeutic option for the treatment of erectile dysfunction (ED). Different studies have demonstrated that PDE5i, by sensitizing insulin target tissues to insulin, play an important role in controlling the action of insulin and glucose metabolism, highlighting the protective action of these drugs against metabolic diseases. In this review, we report the latest knowledge about the role of PDE5i in the metabolic diseases of insulin resistance and type 2 diabetes, highlighting clinical aspects and potential treatment approaches. Although various encouraging data are available, further in vivo and in vitro studies are required to elucidate the mechanism of action and their clinical application in humans.
\end{abstract}

\section{Introduction}

Phosphodiesterases (PDEs) are a family of 11 enzyme isoforms, which hydrolyze cyclic nucleotides to regulate intracellular levels of the second messengers, cyclic adenosine monophosphate (cAMP) and cyclic guanosine monophosphate (cGMP), modulating the duration and intensity of different intracellular functions $[1,2]$. Among these, the isoform 5 (PDE5) hydrolyzes cGMP in an inactive $5^{\prime}$-GMP form, with consequent different cellular responses [3]. The inhibition of this enzyme increases the intracellular level of cGMP, prolonging specific cGMP-related cellular responses. Different drugs inhibiting PDE5 (PDE5i) exist, of which the main substances commercially available are sildenafil, vardenafil, tadalafil, and the more recently approved avanafil [1]. The PDE5i activity has long been used as an effective therapeutic option for the treatment of erectile dysfunction (ED) and for other diseases (i.e., pulmonary hypertension and Raynaud's phenomenon) [3, 4]. However, recent studies have suggested that PDE5i may also be useful in other pathological conditions such as cardiovascular diseases (i.e., coronary artery disease and hypertension) [5-12], autoimmune diseases, and endocrine-metabolic disorders [13-16].

In particular, endocrine-metabolic disorders define a cluster of pathological conditions, which may also greatly increase health risk for cardiovascular diseases [17]. Insulin resistance and obesity are considered the core of most cases of metabolic syndrome and cardiovascular complications where many factors (e.g., endothelial dysfunction, polycystic ovary syndrome (PCOS), hypogonadism, genetic susceptibility, hypertension, and chronic stress) may favor such complications [18]. These metabolic diseases often also induce an alteration of inflammatory status, resulting in increased reactive oxygen species (ROS) production [19].

In this context, due to their observed antioxidant and anti-inflammatory properties, several studies have 
highlighted the protective action of PDE5i against endothelial dysfunction and cardiac ischemic/reperfusion [2]. Furthermore, in vivo and in vitro studies have shown how PDE5 inhibition may ameliorate insulin resistance in diabetic mice [20-22] and sensitize skeletal muscle cells, adipocytes, and endothelial cells to insulin action, thus improving insulin resistance [13, 23-26].

Based on recent in vivo and in vitro findings, this review summarizes the molecular mechanisms that underline the action of PDE5 on intracellular metabolic pathways, the effects of the PDE5i, and the association between PDE5i and metabolic disorders, focusing on glucose metabolism disorders and on the potential therapeutic role of PDE5i to treat insulin resistance and type 2 diabetes.

\section{PDE5-Related Biochemical Pathways}

The biochemical pathways involving PDE5 have largely been studied in smooth muscle cells, investigating the biological basis and mechanism of PDE5i in ED treatment [27]. This mechanism requires the release of nitric oxide (NO) by endothelial cells, its diffusion to smooth muscle cells, and the activation by NO of guanylate cyclase enzyme. The interaction of NO with guanylyl cyclase induces a conformational change in this enzyme, which results in the catalytic production of $3^{\prime}-5^{\prime}$-cyclic guanosine monophosphate from guanosine $5^{\prime}$-triphosphate [28]. Cyclic GMP activates cGMP-dependent protein kinase (PKG), which induces the activation of different substrates. These interactions induce the reduction of intracellular calcium levels and, consequently, relaxation of arterial and trabecular smooth muscle, leading to arterial dilatation, venous constriction, and penile rigidity [29]. PDE5, which is abundant in vascular smooth muscle cells (VSMC), normally inhibits this process by degrading cGMP. The balance between cGMP synthesis by guanylyl cyclase and cGMP hydrolysis by PDE5 regulates cGMP levels in the corpora cavernosa [30]. Various pathological conditions, such as structural and functional endothelium deterioration, insufficient NO production, excessive cGMP hydrolysis by PDE5, and reduction of the conformity of the VSMC and of the connective tissue of the penis (or a combination of the above), can compromise this process.

PDE5i has the capacity to lower the activity of PDE5 by competing with cGMP, subsequently raising its level in the cells $[1,2,28-30]$; thus, the action of the PDE5i is useful to promote the accumulation of cGMP and to potentiate the effect of NO [1].

\section{Molecular Basis of PDE5 Inhibitor Action on Insulin Target Tissues}

Besides the abovementioned effects, data suggest that PDE5i could target insulin-sensitive cells, such as skeletal muscle cells, adipocytes, hepatocytes, and endothelial cells, through an insulin-like effect $[13,22-24,31,32]$. Moreover, PDE5 and nitric oxide synthase (NOS) have been shown to be highly expressed in different tissues commonly involved in glucose metabolism regulation [33-35].
Molecular studies carried out in the skeletal muscle have demonstrated that the inhibition of PDE5 may activate the same downstream pathways related to the action of insulin [13, 24, 31] (Figure 1). In particular, studies in human skeletal muscle cells maintained in normoglycemic conditions showed that a single dose of tadalafil induced, over a few minutes, the following: (a) an increase of glucose transporter (GLUT) 4 gene expression; (b) activation of the peroxisome proliferator-activated receptor gamma (PPAR $\gamma)$ and insulin receptor substrate (IRS)-1; (c) stimulation of the phosphorylation of IRS-1, protein-kinase B (PKB/AKT), mammalian target of rapamycin (mTOR), and glycogen synthase kinase 3 beta (GSK3 $\beta$ ); and (d) translocation on the plasmatic membrane of GLUT4, caveolin-1, and flotillin-1 [13]. Other studies have demonstrated the involvement of $\mathrm{NO} / \mathrm{cGMP}$-related pathways in metabolism regulation, both in skeletal muscle cells and in other insulin-dependent cells; particularly adipocytes and endothelium [36]. NO and cGMP activate PKG, playing an important role in mediating insulin-induced effects, especially favoring glucose uptake, insulin-related pathway activation (e.g., AKT and IRS-1), and GLUT4 translocation $[22,25,37,38]$, as well as inducing the activation of sirtuin-1 (SIRT1), a key sensor of cellular energy status [39-42]. Furthermore, it has been reported that NO release induces 5-AMP activated protein kinase (AMPK) [38], an enzyme which promotes glucose transport and fatty acid oxidation in insulin-responsive tissues [43, 44] and increases GLUT4, mitochondrial proteins, and several metabolic enzymes expression after metabolic challenges [45-48]. Thus, by interfering at various levels with insulinrelated pathways, PDE5i may have different pharmacological effects influencing the regulation of glucose metabolism.

\section{PDE5 Inhibitors and Insulin Resistance}

Insulin resistance (IR) is a pathological condition in which the action of insulin, which aims to facilitate glucose uptake and metabolism in peripheral tissues, is reduced [49]. IR is a basic feature of the etiology in different metabolic disorders and has been linked to a wide range of other pathophysiologic sequelae, including type 2 diabetes, hypertension, hyperlipidemia, and obesity [49]. Evidence suggests that, by targeting insulin-sensitive cells, PDE5 inhibition may contribute to the improvement of insulin resistance (Figure 2); in particular, in skeletal muscles, adipocytes, hepatocytes, and endothelial cells $[13,22,24,30,32]$. As previously mentioned, different studies have demonstrated the direct effect of PDE5 inhibition on insulin pathway activation in skeletal muscle cells [13], suggesting a pivotal role of PDE5 in glucose metabolism regulation. To evaluate the functional role of PDE5 in the muscle tissue, Liu at al. performed molecular studies on differentiated mice muscle cells maintained in hyperglycemic conditions and explained why counteracting PDE5 may be a good strategy for ameliorating insulin sensitivity [49]. The authors demonstrated that, among all the characterized isoforms [50], the overexpression of PDE5A negatively regulated insulin signaling, with a decrease of the activation of insulin pathways and an inhibition of glucose uptake. Moreover, the authors 


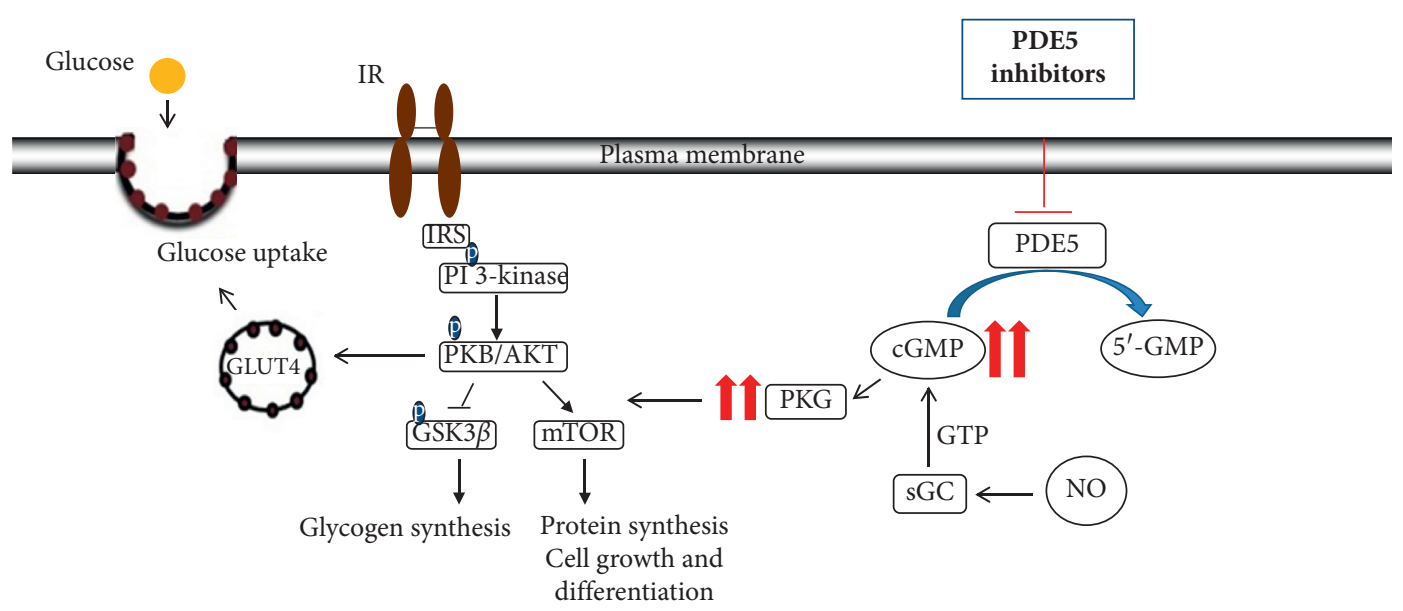

FIGURE 1: Schematic representation of PDE5i action in insulin-related pathways. PKG activated by cGMP exerts positive effects on IRS downstream effectors. The phosphorylation of $\mathrm{PKB} / \mathrm{AKT}$ induces the translocation of GLUT4 vesicles on plasma membrane, favoring glucose uptake and activation of downstream signaling involved in protein synthesis, cell growth, and differentiation. The balance between cGMP synthesis (induced by the interaction of NO with sGC) and cGMP hydrolysis (by PDE5) regulates cGMP levels. The action of the PDE5i promotes the accumulation of cGMP. IR: insulin receptor; NO: nitric oxide; sGC: guanylyl cyclase; PDE5: phosphodiesterase type 5; GMP: guanosine monophosphate; cGMP: cyclic guanosine monophosphate; IRS: insulin receptor substrate; PI3K: phosphatidilinositol 3kinase; $\mathrm{PKB} / \mathrm{AKT}$ : protein kinase $\mathrm{B} / \mathrm{AKT}$; and mTOR: mammalian target of ramapycin.

suggested that this mechanism involves endoplasmic reticulum (ER) and the proteasome activity, two primary elements which regulate the synthesis, viability, folding, and assembly of all secretory, cellular, and membrane proteins [49].

Many studies have reported that NO signaling and its downstream effectors could play an important role in the improvement of inflammation and peripheral insulin resistance [51]. Furthermore, insulin also stimulates NO production in multiple organs involved in glucose metabolism [26, 51].

In endothelial cells maintained in growth conditions mimicking insulin resistance, it has been demonstrated that sildenafil improved the NOS activity by partially involving the activation of the phosphatidylinositol 3-kinase (PI3K) pathway [26]. Furthermore, in hyperglycemic conditions, when e-NOS and AKT-1 activation were reduced, sildenafil treatment restored normal protein function. Interestingly, the oxidative stress induced by hyperglycaemia in endothelial cells was also reduced by sildenafil treatment [26].

Different data have highlighted the role of the $\mathrm{NO} /$ cGMP/PKG pathway in adipocytes as well, given that PDE5 is highly expressed in these cells [22, 23]. Studies carried out in 3T3L1 mice preadipocyte cells demonstrated that chronic treatment with sildenafil for 8 days significantly promoted adipogenesis, increasing lipid droplet and triglyceride content. Moreover, sildenafil treatment increased the expression of the genes and proteins aP2, GLUT4, CCAAT enhancer-binding proteins (C/EBP) $\alpha$ and $\beta$, and PPAR $\gamma$ and upregulated glucose uptake through $\mathrm{PKG}$ activation [52]. Finally, PDE5 inhibitors can promote adipogenesis, interfere with adipokine secretion, decrease inflammatory marker expression, and increase the thermogenic potential of the white adipose tissue and brown adipocyte differentiation [53].
These experiments have been confirmed in animal models, where it has been demonstrated that both acute and chronic treatments with sildenafil could improve insulin resistance and the associated endothelial dysfunction [54-56]. In particular, Ayala et al. demonstrated that mice fed an high-fat diet (HFD) treated with sildenafil $(12 \mathrm{mg} / \mathrm{kg} /$ $\mathrm{d}$ for 12 weeks) showed a decreased weight gain and a $30 \%$ decrease in fat mass, compared with vehicle treatment [57]; furthermore, these mice showed an IR reduction, despite elevated daily food intake.

Different studies performed in diet-induced obese animal models have investigated the effects of a new PDE5i, DA-8159, as well as the PDE5i udenafil. In these studies, the authors demonstrated that the oral administration of PDE5i ameliorated body weight, plasma cholesterol and triglyceride levels, visceral fat mass, cumulative caloric intake, and plasma leptin concentration in comparison with vehicletreated mice $[58,59]$.

In addition, a high-fat diet is able to induce IR in the liver and the proinflammatory activation of Kupffer cells, the resident macrophages of the liver [37]. Furthermore, an event often observed in association with obesity is a reduction in NO vascular content, which may lead to predisposition to increased endothelial and Kupffer cell inflammation, thrombosis, and vasoconstriction [60, 61]. Thus, targeting NO may represent a good strategy for ameliorating the inflammation induced by nutrient excess. In this context, in NO-/- mice fed with a low-fat diet, the authors showed that liver inflammation and IR induced by deficiency of NO/cGMP were comparable with that induced by a high-fat diet. Furthermore, they observed that these effects were prevented by daily oral dosing of sildenafil, supporting the hypothesis of the pivotal role of NO/cGMP signaling in protecting against liver IR and inflammation associated with diet-induced obesity $[37,62]$. The potential 


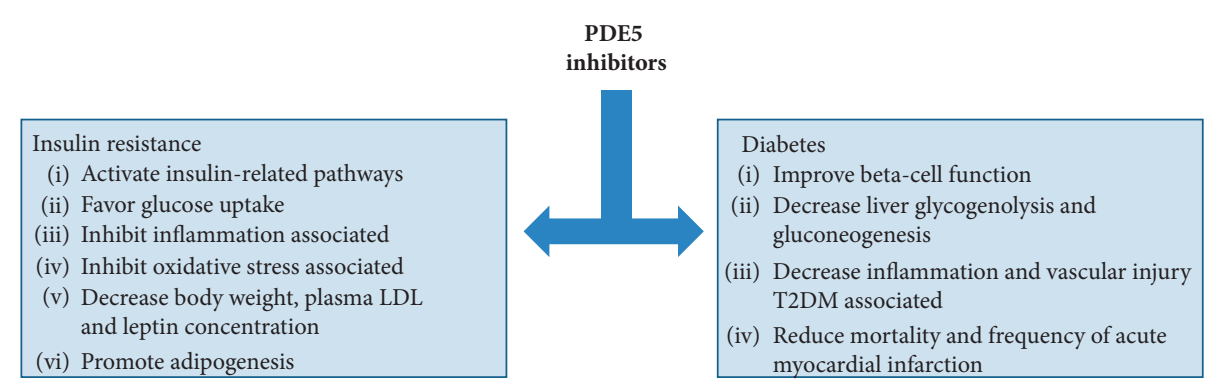

Figure 2: Pivotal roles of PDE5i in glucose metabolic disorders. Schematic image summarizing the main effects of PDE5 inhibitors in insulin resistance and diabetes. LDL: low-density lipoprotein and T2DM: type 2 diabetes mellitus.

usefulness of PDE5i administration in IR conditions and obesity IR-associated has also been partially demonstrated in humans, although further studies are warranted. In a randomized, double-blind trial in subjects with severe obesity $\left(B M I \geq 36.2 \mathrm{~kg} / \mathrm{m}^{2}\right)$ and elevated fasting insulin levels, treatment with tadalafil $(20 \mathrm{mg} / \mathrm{d})$ improved IR and beta-cell function, compared to placebo [63].

\section{PDE5 Inhibitors and Diabetes}

Type 2 diabetes mellitus (T2DM) represents the predominant type of diabetes, which accounts for nearly $90 \%$ of the population with diabetes. It is characterized by high blood sugar and insulin resistance [64]. In this population, PDE5i (particularly tadalafil and sildenafil) have been proven not only to be safe in diabetic men experiencing ED $[59,65,66]$ but also to directly control metabolism regulation as T2DM tends to ameliorate after specific PDE5 inhibition (Figure 2) [20, 22].

Several studies have focused on the use of the PDE5i to treat inflammation, vascular injury, and hepatic diseases often associated with diabetes in both animal models and humans [67-69].

In fact, the hyperglycemic condition in T2DM patients is often associated with systemic inflammation [70, 71]. This is mainly due to an increase of inflammatory cells binding the endothelium [72] and to an increase of cytokine and chemokine production by peripheral blood mononuclear cells (PBMCs). In this context, Varma et al. demonstrated that treatment with tadalafil for 28 days in $\mathrm{T} 2 \mathrm{DM} \mathrm{db} / \mathrm{db}$ mice significantly reduced the levels of the proinflammatory cytokines tumor necrosis factor (TNF)- $\alpha$ and interleukin (IL) $-1 \beta$ and increased that of anti-inflammatory IL-10 [16]. Analogous results were obtained in diet-induced obese (DIO) mice [69] where the authors showed that the combined therapy of PDE5i with leucine administration amplified the effects of PDE5 inhibition, resulting in fatty acid oxidation activation, insulin sensitivity improvement, and reversal of hepatic steatosis. Furthermore, at the same time, the activation of PKG significantly reduced the levels of proinflammatory cytokines commonly upregulated in diabetes [69].

Preclinical studies in patients affected by T2DM with cardiovascular complications showed an improvement in diabetic cardiomyopathy following chronic treatment with sildenafil $100 \mathrm{mg} / \mathrm{d}$ [14], as well as serum decreases of C-Xmotif chemokine 10 (CXCL10) [6] - an important trigger of inflammation-and the cytokine IL-8, which is responsible for a wide range of inflammatory processes and vascular bed injury [5]. Other studies performed in T2DM patients have reported the advantage of sildenafil treatment for diabetic neuropathy and vasculopathy prevention [73] and demonstrated a significant improvement of endothelial function following both acute and chronic sildenafil administration (100 mg/d for 3 days and $25 \mathrm{mg} / \mathrm{d}$ for 4 weeks, respectively) [73-75]. Grover-Paez et al. demonstrated that daily treatment with sildenafil $(50 \mathrm{mg} / \mathrm{d}$ for 30 days) improved both endothelial functional and reduced albuminuria and glycated hemoglobin (HbAlc), suggesting an effect of PDE5i also on endothelial cells [76]. Moreover, an in vivo study conducted on 5956 T2DM patients demonstrated a significant reduction of mortality and a lower frequency of acute myocardial infarction in subjects taking PDE5i [77]. In postmenopausal females with T2DM, an improvement in metabolic parameters after tadalafil administration was reported; in particular, patients exhibited a lower permeability surface area for glucose (PSglu) and an increase of lactate concentration both in muscle and adipose tissues [78].

A recent randomized study performed on T2DM patients and $\mathrm{db} / \mathrm{db}$ mice receiving sildenafil $(100 \mathrm{mg} / \mathrm{d})$ or placebo for 12 weeks showed significant upregulation of miR-22-3p and SIRT1 protein expression [79]. While miR$22-3 p$ is known to be involved in cardiac hypertrophy and remodeling, SIRT1 is an important director of the metabolic response to fasting in mammals; while its overexpression reduces insulin resistance and promotes lipid mobilization in adipocytes [79].

Unfortunately, no adequate data exist to fully understand all of the molecular processes involved in the observed effects of PDE5i in T2DM. For example, the continued excess of glucose release by the liver and beta-cell dysfunction play important roles in the pathogenesis of T2DM $[80,81]$. Accordingly, a study conducted in rat liver cells demonstrated that sildenafil decreased liver glycogenolysis and gluconeogenesis; in particular, treatment with a high dose of PDE5i $(5 \mathrm{mg} / \mathrm{kg})$ reduced the hepatic glycogen phosphorylase (GP), which breaks up glycogen into glucose subunits, without affecting the phosphoenolpyruvate 
carboxykinase enzyme, which participates in gluconeogenesis in animal tissues [82].

Moreover, studies performed in patients affected by metabolic syndrome reported that the administration of tadalafil could improve beta-cell function. Interestingly, the authors showed a significant effect after tadalafil treatment only in female patients who demonstrated more sensitivity to cGMP stabilization than males $[83,84]$. In a double-blind placebo-controlled study of T2DM patients randomized to receive sildenafil $(100 \mathrm{mg} / \mathrm{d}$ for 12 weeks), a reduction of waist circumference (WC) and a reduction of the epicardial adipose tissue (EAT) were observed and compared to placebo, without changes in body weight or body mass index (BMI) [79].

The results of these studies underline the potential usefulness of PDE5 inhibition in T2DM, not only for metabolic control but also for the associated inflammatory status and vascular damage.

\section{Conclusions}

Besides their well-known effects on ED, different preclinical and clinical studies on the use of PDE5 inhibitors for metabolic disease treatment have been conducted. Indeed, PDE5 enzymes are highly expressed in all insulin-sensitive tissues, such as endothelium, muscle, adipocytes, and hepatocytes. Moreover, PDE5i interfere with the NO/cGMP signaling, an important pathway which controls glucose metabolism regulation. Thus, by regulating NO/cGMP pathways, PDE5i administration could provide a good strategy to promote glucose uptake and may be a new pharmacological approach to treat metabolic diseases (Figure 2).

Given the safety record of these drugs, it is desirable to speculate on the use of PDE5 inhibition as a potential approach in the prevention of diet-induced IR and metabolic imbalances. Although different encouraging data are available, further in vivo and in vitro indications are mandatory.

\section{Conflicts of Interest}

The authors declare that they have no conflicts of interest.

\section{Authors' Contributions}

C.A., P.S., and L.D.L. wrote and contributed to revise the final manuscript. All authors have read and agreed to the published version of the manuscript.

\section{Acknowledgments}

This work was supported by the Italian Ministry of Education, University and Research (MIUR) and by the Scientific Independence of Young Researchers (SIR) Program under grant no. RBSI14D5NX.

\section{References}

[1] V. Boswell-Smith, D. Spina, and C. P. Page, "Phosphodiesterase inhibitors," British Journal of Pharmacology, vol. 147, no. S1, pp. 252-257, 2006.

[2] A. Das, D. Durrant, F. N. Salloum, L. Xi, and R. C. Kukreja, "PDE5 inhibitors as therapeutics for heart disease, diabetes and cancer," Pharmacology \& Therapeutics, vol. 147, pp. 1221, 2015.

[3] D. P. Rotella, "Phosphodiesterase 5 inhibitors: current status and potential applications," Nature Reviews Drug Discovery, vol. 1, no. 9, pp. 6746-6782, 2002.

[4] M. Doumas, A. Lazaridis, N. Katsiki, and V. Athyros, "PDE-5 inhibitors: clinical points," Current Drug Targets, vol. 16, no. 5, pp. 420-426, 2015.

[5] S. Giannattasio, C. Corinaldesi, M. Colletti et al., "The phosphodiesterase 5 inhibitor sildenafil decreases the proinflammatory chemokine IL-8 in diabetic cardiomyopathy: in vivo and in vitro evidence," Journal of Endocrinological Investigation, vol. 42, no. 6, pp. 715-725, 2019.

[6] L. Di Luigi, C. Corinaldesi, M. Colletti et al., "Phosphodiesterase type 5 inhibitor sildenafil decreases the proinflammatory chemokine CXCL10 in human cardiomyocytes and in subjects with diabetic cardiomyopathy," Inflammation, vol. 39, pp. 1238-1252, 2016.

[7] R. Kukreja, R. Ockaili, and F. Salloum, "Cardioprotection with phosphodiesterase-5 inhibition-a novel preconditioning strategy," Journal of Molecular and Cellular Cardiology, vol. 36, no. 2, pp. 165-173, 2004.

[8] R. C. Kukreja, F. N. Salloum, and A. Das, "Emerging new uses of phosphodiesterase- 5 inhibitors in cardiovascular diseases," Experimental \& Clinical Cardiology, vol. 16, no. 4, pp. 30-35, 2011.

[9] K. L. Black, D. Yin, J. M. Ong et al., "PDE5 inhibitors enhance tumor permeability and efficacy of chemotherapy in a rat brain tumor model," Brain Research, vol. 1230, pp. 290-302, 2008.

[10] L. Booth, J. L. Roberts, N. Cruickshanks et al., "Phosphodiesterase 5 inhibitors enhance chemotherapy killing in gastrointestinal/genitourinary cancer cells," Molecular Pharmacology, vol. 85, no. 3, pp. 408-419, 2014.

[11] T. K. Hamilton, N. Hu, K. Kolomitro et al., "Potential therapeutic applications of phosphodiesterase inhibition in prostate cancer," World Journal of Urology, vol. 31, no. 2, pp. 325-330, 2013.

[12] J. L. Roberts, L. Booth, A. Conley et al., "PDE5 inhibitors enhance the lethality of standard of care chemotherapy in pediatric CNS tumor cells," Cancer Biology \& Therapy, vol. 15, no. 6, pp. 758-767, 2014

[13] F. Marampon, C. Antinozzi, C. Corinaldesi et al., "The phosphodiesterase 5 inhibitor tadalafil regulates lipidic homeostasis in human skeletal muscle cell metabolism," Endocrine, vol. 59, no. 3, pp. 602-613, 2018.

[14] E. Giannetta, A. M. Isidori, N. Galea et al., "Chronic inhibition of cGMP phosphodiesterase 5A improves diabetic cardiomyopathy," Circulation, vol. 125, no. 19, pp. 2323-2333, 2012.

[15] S. Koka, H. S. Aluri, L. Xi, E. J. Lesnefsky, and R. C. Kukreja, "Chronic inhibition of phosphodiesterase 5 with tadalafil attenuates mitochondrial dysfunction in type 2 diabetic hearts: potential role of NO/SIRT1/PGC- $1 \alpha$ signaling," American Journal of Physiology-Heart and Circulatory Physiology, vol. 306, no. 11, pp. 1558-1568, 2014. 
[16] A. Varma, A. Das, N. N. Hoke et al., "Anti-inflammatory and cardioprotective effects of tadalafil in diabetic mice," PLoS One, vol. 7, no. 9, Article ID e45243, 2012.

[17] E. L. Hoffman, T. VonWald, and K. Hansen, "The metabolic syndrome," South Dakota Medicine: the Journal of the South Dakota State Medical Association..vol. 24-28, 2015.

[18] J. Kaur, "A comprehensive review on metabolic syndrome," Cardiology Research and Practice, vol. 2014, Article ID 943162, 21 pages, 2014.

[19] S. J. Forrester, D. S. Kikuchi, M. S. Hernandes, Q. Xu, and K. K. Griendling, "Reactive oxygen species in metabolic and inflammatory signaling," Circulation Research, vol. 122, no. 6, pp. 877-902, 2018.

[20] C. E. Ramirez, H. Nian, C. Yu et al., "Treatment with sildenafil improves insulin sensitivity in prediabetes: a randomized, controlled trial," The Journal of Clinical Endocrinology \& Metabolism, vol. 100, no. 12, pp. 4533-4540, 2015.

[21] L. Sjögren, J. Olausson, L. Strindberg et al., "Postprandial effects of the phosphodiesterase- 5 inhibitor tadalafil in people with well-controlled type 2 diabetes mellitus: a randomized controlled trial," Diabetic Medicine, vol. 33, no. 9, pp. 12991301, 2016.

[22] A. Aversa, "Systemic and metabolic effects of PDE5-inhibitor drugs," World Journal of Diabetes, vol. 1, no. 1, pp. 3-7, 2010.

[23] H. M. Yu, H. K. Chung, K. S. Kim, J. M. Lee, J. H. Hong, and K. S. Park, "PDE 5 inhibitor improves insulin sensitivity by enhancing mitochondrial function in adipocytes," Biochemical and Biophysical Research Communications, vol. 493, no. 1, pp. 631-636, 2017.

[24] S. Sabatini, P. Sgrò, G. Duranti, R. Ceci, and L. D. Luigi, "Tadalafil alters energy metabolism in C2C12 skeletal muscle cells," Acta Biochimica Polonica, vol. 58, no. 2, pp. 237-241, 2011.

[25] A. Aversa, S. Fittipaldi, D. Francomano et al., "Tadalafil improves lean mass and endothelial function in nonobese men with mild ED/LUTS: in vivo and in vitro characterization," Endocrine, vol. 56, no. 3, pp. 639-648, 2017.

[26] C. Mammi, D. Pastore, M. F. Lombardo et al., "Sildenafil reduces insulin-resistance in human endothelial cells," PLoS One, vol. 6, no. 1, Article ID e14542, 2011.

[27] P. Sandner, J. Hütter, H. Tinel, K. Ziegelbauer, and E. Bischoff, "PDE5 inhibitors beyond erectile dysfunction," International Journal of Impotence Research, vol. 19, no. 6, pp. 533-543, 2007.

[28] P. B. Massion and J.-L. Balligand, "Modulation of cardiac contraction, relaxation and rate by the endothelial nitric oxide synthase (eNOS): lessons from genetically modified mice," The Journal of Physiology, vol. 546, no. 1, pp. 63-75, 2003.

[29] S. H. Francis, J. L. Busch, and J. D. Corbin, "cGMP-dependent protein kinases and cGMP phosphodiesterases in nitric oxide and cGMP action," Pharmacological Reviews, vol. 62, no. 3, pp. 525-563, 2010.

[30] A. Das, L. Xi, and R. C. Kukreja, "Protein kinase G-dependent cardioprotective mechanism of phosphodiesterase- 5 inhibition involves phosphorylation of ERK and GSK $3 \beta$," Journal of Biological Chemistry, vol. 283, no. 43, pp. 2957229585, 2008.

[31] C. Crescioli, N. Sturli, M. Sottili, P Bonini, A Lenzi, and L Di Luigi, "Insulin-like effect of the phosphodiesterase type 5 inhibitor tadalafil onto male human skeletal muscle cells," Journal of Endocrinological Investigation, vol. 36, no. 11, pp. 1020-1026, 2013.

[32] D. Vicent, J. Ilany, T. Kondo et al., "The role of endothelial insulin signaling in the regulation of vascular tone and insulin resistance," Journal of Clinical Investigation, vol. 111, no. 9, pp. 1373-1380, 2003.

[33] T. J. Bloom, "Cyclic nucleotide phosphodiesterase isozymes expressed in mouse skeletal muscle," Canadian Journal of Physiology and Pharmacology, vol. 80, no. 12, pp. 1132-1135, 2002.

[34] A. Armani, V. Marzolla, G. M. C. Rosano, A. Fabbri, and M. Caprio, "Phosphodiesterase type 5 (PDE5) in the adipocyte: a novel player in fat metabolism?" Trends in Endocrinology \& Metabolism, vol. 22, no. 10, pp. 404-411, 2011.

[35] C.-S. Lin, "Tissue expression, distribution, and regulation of PDE5," International Journal of Impotence Research, vol. 16, no. S1, pp. S8-S10, 2004.

[36] A. S. Deshmukh, Y. C. Long, T. De Castro Barbosa et al., "Nitric oxide increases cyclic GMP levels, AMP-activated protein kinase (AMPK) $\alpha 1$-specific activity and glucose transport in human skeletal muscle," Diabetologia, vol. 53, no. 6, pp. 1142-1150, 2010.

[37] S. Tateya, N. O. Rizzo, P. Handa et al., "Endothelial NO/ cGMP/VASP signaling attenuates Kupffer cell activation and hepatic insulin resistance induced by high-fat feeding," $D i$ abetes, vol. 60, no. 11, pp. 2792-2801, 2011.

[38] V. A. Lira, Q. A. Soltow, J. H. D. Long, J. L. Betters, J. E. Sellman, and D. S. Criswell, "Nitric oxide increases GLUT4 expression and regulates AMPK signaling in skeletal muscle," American Journal of Physiology-Endocrinology and Metabolism, vol. 293, no. 4, pp. E1062-E1068, 2007.

[39] C. Cantó and J. Auwerx, "PGC-1 $\alpha$, SIRT1 and AMPK, an energy sensing network that controls energy expenditure," Current Opinion in Lipidology, vol. 20, no. 2, pp. 98-105, 2009.

[40] A. P. Gomes, N. L. Price, A. J. Y. Ling et al., "Declining NAD+ induces a pseudohypoxic state disrupting nuclear-mitochondrial communication during aging," Cell, vol. 155, no. 7, pp. 1624-1638, 2013.

[41] N. L. Price, A. P. Gomes, A. J. Y. Ling et al., "SIRT1 is required for AMPK activation and the beneficial effects of resveratrol on mitochondrial function," Cell Metabolism, vol. 15, no. 5, pp. 675-690, 2012.

[42] G. J. Gowans, S. A. Hawley, F. A. Ross, and D. G. Hardie, “AMP is a true physiological regulator of AMP-activated protein kinase by both allosteric activation and enhancing net phosphorylation," Cell Metabolism, vol. 18, no. 4, pp. 556-566, 2013.

[43] T. W. Balon and A. P. Jasman, "Acute exposure to AICAR increases glucose transport in mouse EDL and soleus muscle," Biochemical and Biophysical Research Communications, vol. 282, no. 4, pp. 1008-1011, 2001.

[44] A. C. Smith, C. R. Bruce, and D. J. Dyck, "AMP kinase activation with AICAR further increases fatty acid oxidation and blunts triacylglycerol hydrolysis in contracting rat soleus muscle," The Journal of Physiology, vol. 565, no. 2, pp. 547553, 2005.

[45] J. Stoppani, A. L. Hildebrandt, K. Sakamoto, D. CameronSmith, L. J. Goodyear, and P. D. Neufer, "AMP-activated protein kinase activates transcription of the UCP3 and HKII genes in rat skeletal muscle," American Journal of PhysiologyEndocrinology and Metabolism, vol. 283, no. 6, pp. E1239E1248, 2002.

[46] W. W. Winder, B. F. Holmes, D. S. Rubink, E. B. Jensen, M. Chen, and J. O. Holloszy, "Activation of AMP-activated protein kinase increases mitochondrial enzymes in skeletal muscle," Journal of Applied Physiology, vol. 88, no. 6, pp. 2219-2226, 2000.

[47] D. Zheng, P. S. MacLean, S. C. Pohnert et al., "Regulation of muscle GLUT-4 transcription by AMP-activated protein 
kinase," Journal of Applied Physiology, vol. 91, no. 3, pp. 1073-1083, 2005.

[48] H. Zong, J. M. Ren, L. H. Young et al., "AMP kinase is required for mitochondrial biogenesis in skeletal muscle in response to chronic energy deprivation," Proceedings of the National Academy of Sciences, vol. 99, no. 25, pp. 1598315987, 2002.

[49] W. Liu, X. Tian, T. Wu, L. Liu, Y. Guo, and C. Wanga, "PDE5A suppresses proteasome activity leading to insulin resistance in C2C12 myotube," International Journal of Endocrinology, vol. 2019, Article ID 3054820, 10 pages, 2019.

[50] F. Campolo, A. Zevini, S. Cardarelli et al., "Identification of murine phosphodiesterase $5 \mathrm{~A}$ isoforms and their functional characterization in HL-1 cardiac cell line," Journal of Cellular Physiology, vol. 233, no. 1, pp. 325-337, 2018.

[51] Y. M. Kang, F. Kim, and W. J. Lee, "Role of NO/VASP signaling pathway against obesity-related inflammation and insulin resistance," Diabetes \& Metabolism Journal, vol. 41, no. 2, pp. 89-95, 2017.

[52] X. Zhang, J. Ji, G. Yan et al., "Sildenafil promotes adipogenesis through a PKG pathway," Biochemical and Biophysical Research Communications, vol. 396, no. 4, pp. 1054-1059, 2010.

[53] G. Colombo, M. D. H. P. Colombo, L. D. L. Schiavon, and A. J. D'Acampora, "Phosphodiesterase 5 as target for adipose tissue disorders," Nitric Oxide, vol. 35, pp. 186-192, 2013.

[54] W. A. Hsueh, C. J. Lyon, and M. J. Quiñones, "Insulin resistance and the endothelium," The American Journal of Medicine, vol. 117, no. 2, pp. 109-117, 2004.

[55] H. A. Hadi and J. A. Suwaidi, "Endothelial dysfunction in diabetes mellitus," Vascular Health and Risk Management, vol. 3, no. 6, pp. 853-876, 2007.

[56] P. C. Deedwania, "Diabetes is a vascular disease: the role of endothelial dysfunction in pathophysiology of cardiovascular disease in diabetes," Cardiology Clinics, vol. 22, no. 4, pp. 505-509, 2004.

[57] J. E. Ayala, D. P. Bracy, B. M. Julien, J. N. Rottman, P. T. Fueger, and D. H. Wasserman, "Chronic treatment with sildenafil improves energy balance and insulin action in high fat-fed conscious mice," Diabetes, vol. 56, no. 4, pp. 10251033, 2007.

[58] A. Nakamura, T. Osonoi, and Y. Terauchi, "Relationship between urinary sodium excretion and pioglitazone-induced edema," Journal of Diabetes Investigation, vol. 1, no. 5, pp. 208-211, 2010.

[59] S. Y. Ryu, Y.-J. Choi, S.-Y. Park, J.-Y. Kim, Y.-D. Kim, and Y.-W. Kim, "Udenafil, a phosphodiesterase 5 inhibitor, reduces body weight in high-fat-fed mice," The World Journal of Men's Health, vol. 36, no. 1, pp. 41-49, 2018.

[60] S. Verma and T. J. Anderson, "Fundamentals of endothelial function for the clinical cardiologist," Circulation, vol. 105, no. 5, pp. 546-549, 2002.

[61] V. W. Liu and P. L. Huang, "Cardiovascular roles of nitric oxide: a review of insights from nitric oxide synthase gene disrupted mice," Cardiovascular Research, vol. 77, pp. 19-29, 2008.

[62] X. Liu, J. Y. Huh, H. Gong et al., "Lack of mature lymphocytes results in obese but metabolically healthy mice when fed a high-fat diet," International Journal of Obesity, vol. 39, no. 10, pp. 1548-1557, 2015.

[63] J. E. Ho, P. Arora, G. A. Walford et al., "Effect of phosphodiesterase inhibition on insulin resistance in obese individuals," Journal of the American Heart Association, vol. 11, Article ID e001001, 2014.
[64] I. Hameed, S. R. Masoodi, S. A. Mir, M. Nabi, K. Ghazanfar, and B. A. Ganai, "Type 2 diabetes mellitus: from a metabolic disorder to an inflammatory condition," World Journal of Diabetes, vol. 6, no. 4, pp. 598-612, 2015.

[65] A. Basu and R. E. J. Ryder, "New treatment options for erectile dysfunction in patients with diabetes mellitus," Drugs, vol. 64, no. 23, pp. 2667-2688, 2004.

[66] S. H. Francis and J. D. Corbin, "PDE5 inhibitors: targeting erectile dysfunction in diabetics," Current Opinion in Pharmacology, vol. 11, no. 6, pp. 683-688, 2011.

[67] M. A. Venneri, E. Giannetta, G. Panio et al., "Chronic inhibition of PDE5 limits pro-inflammatory monocyte-macrophage polarization in streptozotocin-induced diabetic mice," PLoS One, vol. 10, no. 5, Article ID e0126580, 2015.

[68] T. Filardi, B. Ghinassi, A. Di Baldassarre et al., "Cardiomyopathy associated with diabetes: the central role of the cardiomyocyte," International Journal of Molecular Sciences, vol. 20, no. 13, p. 3299, 2019.

[69] L. Fu, F. Li, A. Bruckbauer et al., "Interaction between leucine and phosphodiesterase 5 inhibition in modulating insulin sensitivity and lipid metabolism," Diabetes, Metabolic Syndrome and Obesity: Targets and Therapy, vol. 8, pp. 227-239, 2015.

[70] D. Aronson, P. Bartha, O. Zinder et al., “Association between fasting glucose and C-reactive protein in middle-aged subjects," Diabetic Medicine, vol. 21, no. 1, pp. 39-44, 2004.

[71] N. Varo, D. Vicent, P. Libby et al., "Elevated plasma levels of the atherogenic mediator soluble CD40 ligand in diabetic patients," Circulation, vol. 107, no. 21, pp. 2664-2669, 2003.

[72] M. Morigi, S. Angioletti, B. Imberti et al., "Leukocyte-endothelial interaction is augmented by high glucose concentrations and hyperglycemia in a NF-kB-dependent fashion," Journal of Clinical Investigation, vol. 101, no. 9, pp. 1905-1915, 1998.

[73] C. S. Patil, V. P. Singh, S. Singh, and S. K. Kulkarni, "Modulatory effect of the PDE-5 inhibitor sildenafil in diabetic neuropathy," Pharmacology, vol. 72, no. 3, pp. 190-195, 2004.

[74] C. Desouza, A. Parulkar, D. Lumpkin, D. Akers, and V. A. Fonseca, "Acute and prolonged effects of sildenafil on brachial artery flow-mediated dilatation in type 2 diabetes," Diabetes Care, vol. 25, no. 8, pp. 1336-1339, 2002.

[75] A. Aversa, C. Vitale, M. Volterrani et al., "Chronic administration of Sildenafil improves markers of endothelial function in men with type 2 diabetes," Diabetic Medicine, vol. 25, no. 1, pp. 37-44, 2008.

[76] F. Grover-Páez, G. Villegas Rivera, and R. Guillén Ortíz, "Sildenafil citrate diminishes microalbuminuria and the percentage of A1c in male patients with type 2 diabetes," Diabetes Research and Clinical Practice, vol. 78, no. 1, pp. 136-140, 2007.

[77] S. G. Anderson, D. C. Hutchings, M. Woodward et al., "Phosphodiesterase type- 5 inhibitor use in type 2 diabetes is associated with a reduction in all-cause mortality," Heart, vol. 102, no. 21, pp. 1750-1756, 2016.

[78] G. Murdolo, M. Sjöstrand, L. Strindberg, P. Lönnroth, and P.-A. Jansson, "The selective phosphodiesterase-5 inhibitor tadalafil induces microvascular and metabolic effects in type 2 diabetic postmenopausal females," The Journal of Clinical Endocrinology \& Metabolism, vol. 98, no. 1, pp. 245-254, 2013.

[79] D. Fiore, D. Gianfrilli, E. Giannetta et al., "PDE5 inhibition ameliorates visceral adiposity targeting the miR-22/SIRT1 pathway: evidence from the CECSID trial," The Journal of 
Clinical Endocrinology \& Metabolism, vol. 101, no. 4, pp. 1525-1534, 2016.

[80] P. M. Titchenell, M. A. Lazar, and M. J. Birnbaum, "Unraveling the regulation of hepatic metabolism by insulin," Trends in Endocrinology \& Metabolism, vol. 28, no. 7, pp. 497-505, 2017.

[81] R. Unger, "Lipid overload and overflow: metabolic trauma and the metabolic syndrome," Trends in Endocrinology and Metabolism, vol. 14, no. 9, pp. 398-403, 2003.

[82] S. Hoseini, H. Esmaily, A. Mohammadirad, and M. Abdollahi, "Effects of sildenafil a phosphodiesterase 5 inhibitor on rat liver cell key enzymes of gluconeogenesis and glycogenolysis," International Journal of Pharmacology, vol. 2, no. 3, pp. 280-285, 2006.

[83] K. D. Hill, A. W. Eckhauser, A. Marney, and N. J. Brown, "Phosphodiesterase 5 inhibition improves -cell function in metabolic syndrome," Diabetes Care, vol. 32, no. 5, pp. 857859, 2009.

[84] Y. P. Balhara, S. Sarkar, and R. Gupta, "Phosphodiesterase-5 inhibitors for erectile dysfunction in patients with diabetes mellitus: a systematic review and meta-analysis of randomized controlled trials," Indian Journal of Endocrinology and Metabolism, vol. 19, no. 4, pp. 451-461, 2015. 